Case Report

DOI: http://dx.doi.org/10.18203/issn.2454-5929.ijohns20190785

\title{
Mucoepidermoid carcinoma of buccal mucosa: an unusual presentation
}

\author{
Shravan S. Shetty ${ }^{1 *}$, Ankur Pareek ${ }^{1}$, Yash Devckar ${ }^{1}$, Sameer Pathan ${ }^{2}$
}

${ }^{1}$ Department of Surgical Oncology, ${ }^{2}$ Department of Pathology, Asian Cancer Institute, Mumbai, Maharashtra, India

Received: 15 November 2018

Accepted: 27 December 2018

*Correspondence:

Dr. Shravan S. Shetty,

E-mail: drshravanshetty@gmail.com

Copyright: $\odot$ the author(s), publisher and licensee Medip Academy. This is an open-access article distributed under the terms of the Creative Commons Attribution Non-Commercial License, which permits unrestricted non-commercial use, distribution, and reproduction in any medium, provided the original work is properly cited.

\begin{abstract}
Mucoepidermoid carcinoma (MEC) is the most common malignant tumor of the salivary glands. This tumor usually occurs in the parotid gland and hard palate but rarely in the buccal region. We report the case of a 51 year old lady with mucoepidermoid carcinoma of left buccal mucosa. She was treated successfully with multimodal treatment including surgery, chemotherapy and radiotherapy. MECs have a female predilection and occur most commonly on the hard or soft palate or both and rare in the buccal mucosa.
\end{abstract}

Keywords: Mucoepidermoid carcinoma, Buccal mucosa

\section{INTRODUCTION}

Mucoepidermoid carcinoma (MEC) represents about 5\% of all tumors in the salivary glands. MEC appear as asymptomatic swellings in the minor salivary glands, being the second most common site of occurrence after the parotid gland. Other sites of presentation have been on the palate, in the retromolar area, floor of mouth, buccal mucosa, lips and tongue. ${ }^{1}$

\section{CASE REPORT}

A 51-year-old lady presented with complaint of an ulcer in the inner aspect of left cheek for 6 months. The patient has a history of tobacco chewing which she had quit recently. Oral examination revealed a $4 \times 4 \mathrm{~cm}^{2}$ ulceroproliferative growth on the left buccal mucosa involving the lower gingivobuccal sulcus (GBS) with no palpable neck nodes (Figure 1). Preoperative biopsy done outside was squamous cell carcinoma. CT scan revealed a solid enhancing mass lesion $3.2 \times 1.8 \mathrm{~cm}^{2}$ in the left buccal mucosa and lower gingivobuccal sulcus (GBS) with enlarged level I lymph node. She underwent left buccal mucosa wide excision with left modified neck dissection type 3 (Figure 2). The defect was reconstructed using pectoralis major myofascial flap. Histopathology report showed high grade mucoepidermoid carcinoma of buccal mucosa, maximum tumor size $2.8 \mathrm{~cm}$, PNI+, $4 / 29$ nodes showing mucoepidermoid carcinoma with perinodal infiltration (pT2N2bM0). The patient took concurrent chemo-radiation as adjuvant treatment. Currently, the patient is in follow up with the operative site well healed.

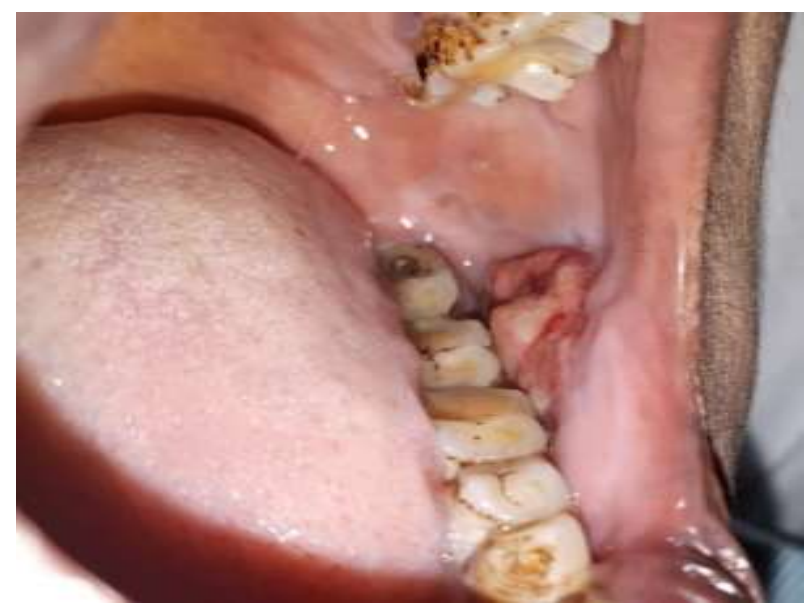

Figure 1: $4 \times 4 \mathrm{~cm}^{2}$ ulceroproliferative growth in left buccal mucosa involving left lower GBS. 


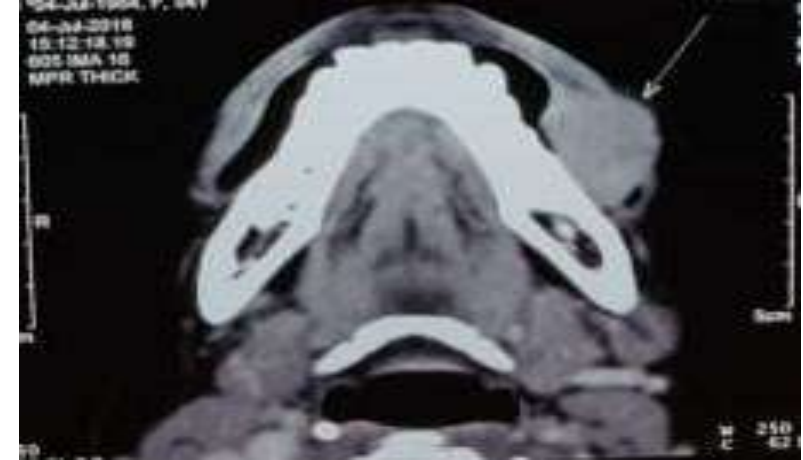

Figure 2: CECT shows a solid enhancing mass lesion in left buccal mucosa and lower GBS with enlarged level I node.

\section{DISCUSSION}

Epithelial salivary gland neoplasms are comparatively rare to occur in adults and children, they account for less than $3 \%$ of all head and neck tumors. ${ }^{2}$ Epithelial malignancies taking origin from the minor salivary glands accounts for about $15 \%$ of all salivary gland neoplasms. $^{3}$

In adults, MECs are most common in the $3^{\text {rd }}$ to $5^{\text {th }}$ decades of life with a female predilection. Smoking, viral infections, working in rubber manufacturing and genetic susceptibility are some of the risk factors found in association with MEC. ${ }^{4}$ Prior exposure to radiation is the only well established and most commonly associated risk factor for development of MEC.

Most commonly MECs present as an asymptomatic, well defined, smooth, nodular lesion which is slow growing and may be present since many months or many years. The clinical features suggesting aggressive behavior are short duration, presence of clinical symptoms and location of tumor in the tongue and the floor of the mouth. ${ }^{5}$ Diagnosis of minor salivary gland tumors is based on clinical history, physical examination supported by imaging such as CT scan or MRI and FNAC. Brandwein et al classified histopathologic grades into low, intermediate or high grade based on following parameters: cystic component $<25 \%$, neural invasion, necrosis, mitoses $>4 / 10 \mathrm{hpf}$, anaplasia, invasion in small nests and islands, lymphatic or vascular invasion and bone invasion. ${ }^{6}$ CT scans reveal well circumscribed masses with cystic features and rarely calcifications for low grade cancers while high grade tumors show a poorly defined lesion with local infiltration with enhancement of solid areas. Radical surgery is the treatment of choice for high grade MECs and for low and intermediate MECs which are large and involve bone. Routine neck dissection is rarely warranted, as the incidence of nodal metastases is low. Many factors dictate neck dissection such as site and size (T) of the tumor, histological grade and age of the patient. Adjuvant radiotherapy to the excision site is often recommended in the setting of positive or close margins, high-grade carcinomas, local invasion into bone or positive lymph nodes. ${ }^{7}$ Overall survival has been linked to histocytologic grade with 95$100 \%$ in low grade and $25-43 \%$ in high grade tumors. ${ }^{8}$

\section{CONCLUSION}

Minor salivary gland tumors have a wide variation in presentation and head and neck surgeons should consider them in differential diagnosis when assessing an intraoral pathology. Mucoepidermoid carcinomas in buccal mucosa are exceedingly rare and low and intermediate grade tumors have $100 \%$ cure rates, but high grade mucoepidermoid carcinomas have poorer prognosis and a greater tendency to infiltrate, recur and metastasize. Thus, patients with these lesions must be considered cautiously for a better clinical outcome.

Funding: No funding sources Conflict of interest: None declared

Ethical approval: Not required

\section{REFERENCES}

1. Hicks J, Flaitz C. Mucoepidermoid carcinoma of salivary glands in children and adolescents: Assessment of proliferation markers. Oral Oncol. 2000;36:454-60.

2. Luna MA, Batsakis JG, El-Naggar AK.Salivary gland tumors in children. Ann Otol Rhinol Laryngol. 1991;100:869-71.

3. Kolude B, Lawoyin JO, Akang EE. Mucoepidermoid carcinoma of the oral cavity. J Natl Med Assoc. 2001;93:178-84.

4. Whatley WS, Thompson JW, Rao B. Salivary gland tumors in survivors of childhood cancers. Otolaryngol Head Neck Surg. 2006;134(3):385-8.

5. Triantafillidou K, Dimitrakopoulos J, Iordanidis F and Koufogiannis D. Mucoepidermoid carcinoma of minor salivary glands: A clinical study of 16 cases and review of literature. Oral Dis. 2006;12:364-70.

6. Brandwein MS, Ivanov K, Wallace DI, Hille JJ, Wang B, Fahmy A, et al. Mucoepidermoid carcinoma: A clinicopathologic study of 80 patients with special reference to histologic grading. Am J Surg Pathol. 2001;25(7):835-45.

7. Hyam D Veness M, Morgan G. Minor salivary gland carcinoma involving the oral cavity or oropharynx. Australian Dental J. 2004;49:16-9.

8. Khadaroo RG, Walton JM, Ramsay JA, Hicks MJ, Archibald SD. Mucoepidermoid carcinoma of the parotid gland: A rare presentation in a young child. $\mathrm{J}$ Pediatr Surg. 1998;33:893-5.

Cite this article as: Shetty SS, Pareek A, Devckar Y, Pathan S. Mucoepidermoid carcinoma of buccal mucosa: an unusual presentation. Int J Otorhinolaryngol Head Neck Surg 2019;5:502-3. 